Cabrião: o debate político no Segundo Reinado por meio das caricaturas de Angelo Agostini

Danilo Aparecido Champan Rocha; Sandra de Cássia Araújo Pelegrini

\title{
CABRIÃO: O DEBATE POLÍTICO NO SEGUNDO REINADO POR MEIO DAS CARICATURAS DE ANGELO AGOSTINI
}

\author{
Danilo Aparecido Champan Rocha ${ }^{1}$ \\ Sandra de Cássia Araújo Pelegrini ${ }^{2}$
}

\begin{abstract}
Resumo: A fundação do Cabrião (1866-1867), segunda revista ilustrada e humorística de São Paulo, editada por Américo de Campos, Antonio Manoel dos Reis e Angelo Agostini, consolidou o potencial da combinação da linguagem verbovisual para noticiar os principais acontecimentos citadinos, os debates políticos e os eventos culturais. A caricatura, técnica de deformação do real por meio do ridículo e da derrisão do objeto retratado, abrangeu o acesso das discussões da imprensa à um público não-letrado e permitiu intensificar a difusão de valores e ideias através de sua mordacidade cáustica. Nesse sentido, o periódico paulistano ilustrado criticou seus adversários políticos, principalmente, os conservadores e os jesuítas, considerados como obstáculos para o "progresso civilizatório". Identificados com o ideário liberal, os redatores defenderam a descentralização política, o ensino laico, a supressão do poder moderador, entre outras medidas, o que muitas vezes ocasionou problemas políticos com seus próprios correligionários. Por fim, a oposição de diversos segmentos sociais da província de São Paulo contra a continuidade da circulação do Cabrião provocou uma crise financeira que impediu a produção de uma segunda série.
\end{abstract}

Palavras-chave: História Cultural; Segundo Reinado; Imprensa Ilustrada; Cabrião.

\section{CABRIÃO: THE POLITICAL DEBATE IN THE SECOND REIGN BY THE ANGELO AGOSTINI'S CARICATURES}

\begin{abstract}
The foundation of Cabrião (1866-1867), second illustrated and humorous magazine of São Paulo, edited by Américo de Campos, Antonio Manoel dos Reis and Angelo Agostini, consolidated the potential of the combination of verbovisual language to report the main city events, political debates and cultural events. The caricature, technique of deformation of the real through ridicule and derision of the object portrayed, covered the access of the press discussions to a non-literate public and allowed to intensify the diffusion of values and ideas through its caustic mordacity. In this sense, the enlightened of São Paulo newspaper criticized its political opponents, especially the conservatives and the Jesuits, considered as obstacles to "civilizational progress". Identified with the liberal ideology, the writers defended the political decentralization, the lay teaching, the suppression of the moderating power, among other measures, which often caused political problems with its own coreligionists. Finally, the opposition of several social segments of the province of São Paulo against the continuity of the Cabrião's circulation caused a financial crisis that prevented the production of a second series.
\end{abstract}

Keywords: Cultural History; Second Reign; Illustrated Press; Cabrião.

\footnotetext{
${ }^{1}$ Doutorando em História pela Universidade Estadual de Maringá (UEM). Mestre em História pela UEM.

${ }^{2}$ Doutora em História Social pela Universidade de São Paulo (USP); Pós-Doutorado em Patrimônio Cultura pela Universidade Estadual de Campinas (UNICAMP). Docente do Departamento de História da Universidade Estadual de Maringá (UEM) onde atua no Ensino de Graduação em História, Arquitetura e Urbanismo, Artes Visuais, e no Programa de Pós Graduação em História da UEM (Mestrado e Doutorado).
}

Fronteiras: Revista de História | Dourados, MS |v. 20 | n. 35 | p. 46 - 67 | Jan. / Jun. 2018 


\section{CABRIÃO: EL DEBATE POLÍTICO EN EL SEGÚN REINADO POR MEDIO DE LAS CARICATURAS DE ANGELO AGOSTINI}

Resumen: La fundación del Cabrião (1866-1867), segunda revista ilustrada y humorística de São Paulo, editada por Américo de Campos, Antonio Manoel dos Reis y Angelo Agostini, consolidó el potencial de la combinación del lenguaje verbo-visual para noticiar los principales acontecimientos citadinos, los debates políticos y los acontecimientos culturales. La caricatura, técnica de deformación del real por medio del ridículo y del derrumbamiento del objeto retratado, abarcó el acceso de las discusiones de la prensa a un público no letrado y permitió intensificar la difusión de valores e ideas a través de su mordacidad cáustica. En ese sentido, el periódico paulistano ilustrado criticó a sus adversarios políticos, principalmente, a los conservadores y los jesuitas, considerados como obstáculos para el "progreso civilizatorio". Identificados con el ideario liberal, los redactores defendieron la descentralización política, la enseñanza laica, la supresión del poder moderador, entre otras medidas, lo que a menudo ocasionó problemas políticos con sus propios correligionarios. Por último, la oposición de diversos segmentos sociales de la provincia de São Paulo contra la continuidad de la circulación del Cabrião provocó una crisis financiera que impidió la producción de una segunda serie.

Palabras clave: Historia Cultural; Según Reinado; Prensa Ilustrada; Cabrião.

\section{INTRODUÇÃO}

A caricatura, representação visual e humorística de uma pessoa, acontecimento, costume ou ideia, deforma o real de modo burlesco, em forma de crítica ou divertimento, técnica encontrada desde a Antiguidade na decoração de utensílios domésticos e de paredes na Grécia e na Roma. Derivada do verbo italiano caricare (carregar, sobrecarregar, com exagero), o desenho caricatural foi difundido na Europa no século XVI, principalmente após a fundação da academia em Borgonha pela família Carracci, e suas obras tiveram forte aceitação social ao retratar as situações ridículas do gênero humano, objeto disputado até por colecionadores no século XVII (FONSECA, 1999). No mesmo período, a caricatura produzida na Holanda incluiu a temática política nas suas sátiras gráficas, cujo alvo central foi Luís XIV, rei da França, o que desafiou, de acordo com Minois (2003, p. 76), a concepção de Platão e Aristóteles sobre o âmbito político como o oposto dos assuntos banais, por isso, reservado as abordagens "sérias" desprovidas de humor.

No século XIX, a intensificação do discurso cômico como ferramenta de crítica nas sátiras políticas ou sociais e a proliferação da imprensa contribuíram para o surgimento de periódicos ilustrados na Europa, compostos pelas linguagens verbal e visual, combinação 
possível graças aos desenvolvimentos técnicos de impressão litográfico e tipográfico. $\mathrm{O}$ conteúdo humorístico dessas revistas, elemento essencial na construção do ridículo, potencializou no discurso verbovisual os "vícios", os "defeitos" e o "grotesco" de uma pessoa, sociedade, costume, religião ou personalidade política. Dessa forma, La Caricature (1830) e Le Charivari (1832), ambas revistas francesas, e o periódico inglês Punch (1841), todas precursoras e de publicação impactantes nas suas sociedades respectivas, abordaram os principais assuntos da época e problematizaram questões para um público mais amplo, inclusive os analfabetos, o que muitas vezes provocou a perseguição e a censura sobre os artistas e seus redatores.

No Brasil, a litografia demorou para se consolidar na imprensa oitocentista, principalmente, pelas limitações técnicas e pelos poucos profissionais capacitados na área. Segundo Sodré (1999, p. 203), a primeira caricatura circulou de forma avulsa em 1837, de autoria de Manuel de Araújo Porto-Alegre (1806-1879), o Barão de Santo Ângelo, professor da Imperial Academia de Belas Artes e considerado o primeiro caricaturista brasileiro. Além da impressão avulsa, caricaturas e imagens foram introduzidas pioneiramente em alguns periódicos como, por exemplo, o Museu Universal: jornal das famílias brasileiras (18381844) e a Lanterna Mágica (1844-1845), ambas as revistas consideradas precursoras nesse gênero no âmbito nacional. ${ }^{3}$

No entanto, a Semana Ilustrada (1860-1876), redigida na corte pelo alemão Henrique Fleiuss (1823-1882), foi um marco na imprensa ilustrada, tanto pela abrangência de suas publicações quanto pelo aumento da qualidade técnica das imagens impressas. Periódico semanal, de oito páginas, dividido entre ilustração e texto verbal, conforme Nery (2011, p. 175), abordou de forma crítica nas suas caricaturas o cotidiano citadino, os costumes de seus habitantes, as novas formas de sociabilidade e as transformações do espaço urbano ocorridos ao longo do processo de expansão de uma sociedade burguesa no Rio de Janeiro.

Em São Paulo, a inexistência de uma imprensa sólida com produção contínua e de longa duração, durante a primeira metade do século XIX, foi um reflexo de sua economia de subsistência e do status de segunda grandeza da província. Por isso, a fundação do Cabrião (1866-1867), revista ilustrada por Angelo Agostini, o mesmo caricaturista do Diabo Coxo

\footnotetext{
${ }^{3}$ Há uma divergência interpretativa entre Sodré (1999) e Cardoso (2011) sobre qual seria a primeira revista ilustrada no Brasil. Para aprofundar as discussões, ver: SODRÉ, Nelson W. História da imprensa no Brasil. 4. Ed. Rio de Janeiro: Mauad, 1999; CARDOSO, Rafael. Projeto gráfico e meio editorial nas revistas ilustradas do Segundo Reinado. In: KNAUSS, Paulo; MALTA Marize; OLIVEIRA, Cláudia de; VELLOSO, Mônica Pimenta (Orgs.). Revistas Ilustradas: modos de ver e ler no Segundo Reinado. Rio de Janeiro: Mauad X: FAPERJ, 2011.
} 
(1864-1865) que foi o primeiro periódico a combinar a linguagem verbal e visual nas suas publicações em São Paulo, significou um marco para a imprensa paulista e consolidou o gênero como forma de narrar os eventos políticos, sociais, culturais, econômicos e do cotidiano citadino. Além de Agostini, Américo de Campos e Antonio Manoel dos Reis participaram da redação do Cabrião, porém, a escassez de fontes não nos permitiu obter mais informações sobre a relação do trio, a não ser o viés político liberal como um elemento aglutinador.

Jornal domingueiro, a folha humorística reproduziu o modelo editorial da Semana Ilustrada e dividiu cada número em oito páginas, quatro ilustradas com caricaturas e quatro com textos de notícias, poesias, entre outras temáticas. Do mesmo modo, o Cabrião também adotou dois personagens-símbolos para encarnar as opiniões da revista, o Cabrião e o Sr. Thomaz, ambos empenhados em denunciar os "vícios" daquela sociedade. A inspiração para o personagem central e o nome do semanário foi baseada na literatura de um importante escritor francês, Joseph Marie Sue (1804-1857), mais conhecido como Eugène Sue. Em Os Mistérios de Paris (1842), o personagem Cabrião, nome aportuguesado de Cabrion, foi um pintor residente na pousada de Alfred Pipelet e Pomona Fortunata Anastasie Pipelet, caracterizado como uma figura inoportuna e incômoda, responsável por infernizar a vida do sr. e da sra. Pipelet. Paralelamente, podemos deduzir como a escolha do nome transpôs a intenção dos redatores de incomodar determinados segmentos sociais da mesma forma que seu homônimo ficcional e, assim, "corrigi-los" por meio do riso, conduta presente na construção cômica e irônica das caricaturas e das seções verbais como demonstraremos a seguir.

\section{CABRIÃO: IMPRENSA E HUMOR EM SÃO PAULO}

No decorrer de suas publicações, as denúncias do Cabrião atingiram diversos grupos sociais da cidade, aumentando a oposição contra o periódico. Porém, como prometido na apresentação do primeiro número, nenhum grupo foi tão criticado quanto os jesuítas e os conservadores. Para evitar qualquer mal-entendido, os redatores reafirmaram o seu posicionamento ideológico e seus adversários no segundo número.

Si vera est fama, as palavras do Cabrião, não foram bem traduzidas, fazendo-se mister uma interpretação dotrinal. Lá váe. O Cabrião foi crêado 
para môer a paciencia dos jesuitas, para amolar os vinagres, para enforcar todos os cascudos existentes e por existir. [...] O Cabrião tem em vista dar caça as beatas, e á sucia de marmanjos, que depois de ter pintado o padre, vestiram a opa e vivem de orar a Deos, e beijar a dextra dos barbados. Querem que a sua missão seja preparar o terreno para o pleito eleitoral. Upa! É isso e mais alguma cousinha (Cabrião, 2000 [1866], p. 10, grifo do autor $)^{4}$.

De forma mais explícita e direcionada, os redatores exibiram como o periódico "foi criado para moer a paciência dos jesuítas, para amolar os vinagres, para enforcar todos os cascudos existentes e por existir", ou seja, o semanário tinha por maior objetivo criticar os seus dois adversários principais: os conservadores (vinagres/cascudos) e os jesuítas. Interessante ressaltarmos o fato do Cabrião abordar incisivamente os jesuítas, além de parte do clero secular e das ordens religiosas, pela prática generalizada de segmentos religiosos de interferirem no sistema eleitoral a favor dos conservadores, situação sublinhada ironicamente no trecho acima ao conceber a sua "missão" na terra a de preparar os fiéis para o pleito eleitoral.

O semanário, além de promover a extinção da Companhia de Jesus e suas principais bandeiras, também denunciava os privilégios e a vida "feliz" desse segmento que pregava o ascetismo e a expiação. O mote da gula e da hipocrisia foram explorados inúmeras vezes pelo periódico para retratar os "vícios" dos integrantes do clero, como Agostini abordou na caricatura seguinte.

\footnotetext{
${ }^{4}$ Optamos por transcrever as passagens retiradas da fonte na forma ortográfica da época.
} 
Figura 1: "A gula"

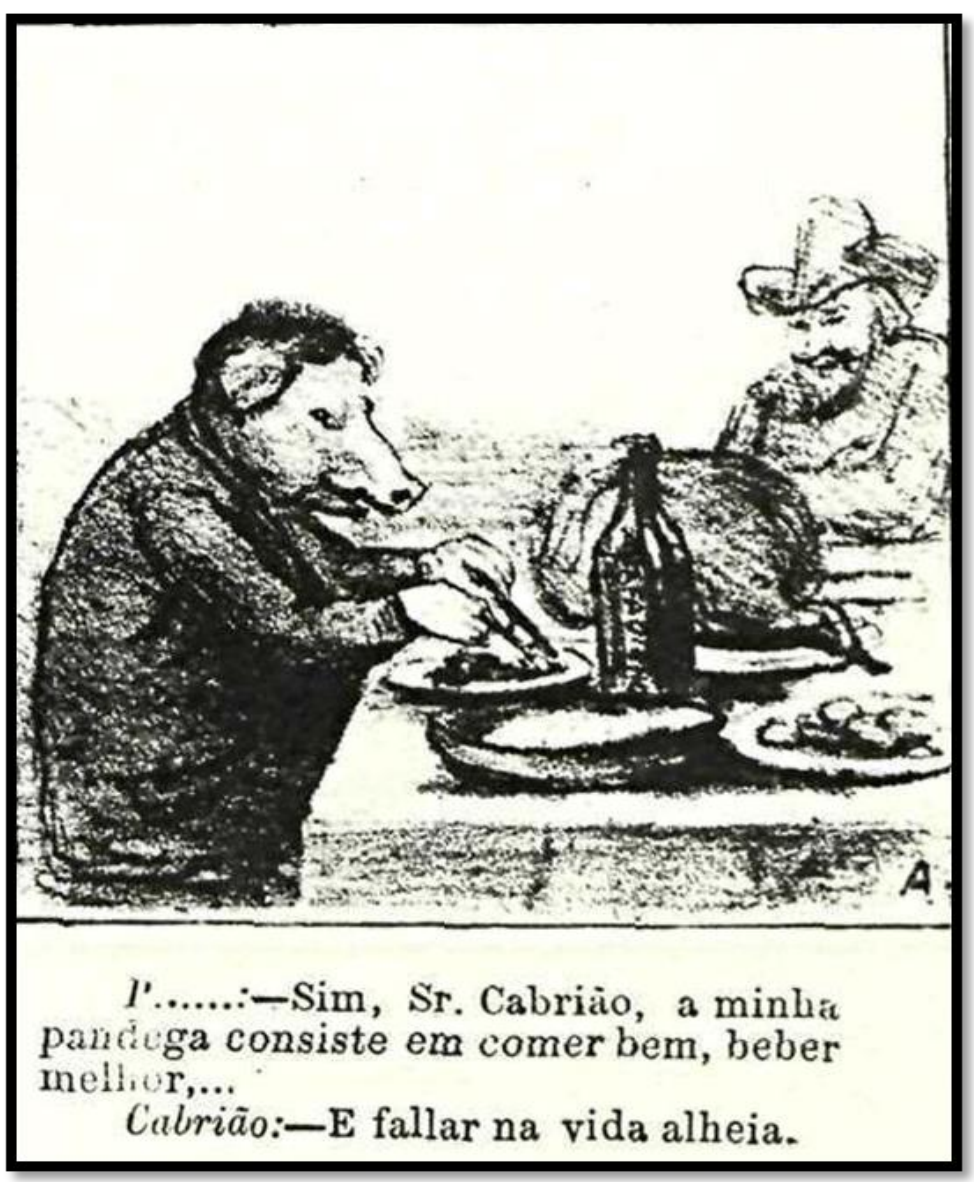

Fonte: Cabrião, São Paulo, n. 3, 1866, p. 05.

No primeiro plano, um porco faz uma refeição, vestido com roupas masculinas e sentado à mesa conforme exigiam as regras de etiqueta. $\mathrm{O}$ personagem Cabrião, o acompanha e observa o seu banquete. No diálogo, o suíno explicou como a sua "pândega" consistia em "comer bem" e "beber melhor". Nomeado com a letra "p", a abreviação podia indicar a palavra porco, combinação convergente com a linguagem visual, mas diante das descrições e do posicionamento da revista, também podia apontar implicitamente o vocábulo 'padre', ambiguidade apresentada para a interpretação do público. A representação do porco, juntamente com a do asno, também foi uma forma de satirizar a Igreja e o clero, principalmente, nas manifestações populares antirreligiosas na França do século XIX (MINOIS, 2003). Dessa forma, compreendemos a letra "p" como uma estratégia dos redatores para sugerir implicitamente se tratar de um "padre" e não para abreviar a palavra porco.

O traço exagerado na representação da barriga do eclesiástico retomou a ideia da gula, no sentido de ressaltar o excesso desvirtuoso e a fartura das refeições, abundância 
Cabrião: o debate político no Segundo Reinado por meio das caricaturas de Angelo Agostini Danilo Aparecido Champan Rocha; Sandra de Cássia Araújo Pelegrini

caracterizada pela garrafa de vinho, sem nenhum copo para dosar o consumo, e um pernil inteiro em cima da mesa, entre outros alimentos. Como ironizado em outras passagens e caricaturas, lugar de cozinha decente era no Seminário (Cabrião, 2000 [1866], p. 41), digno da presença de um cozinheiro francês cordon bleu (Cabrião, 2000 [1866], p. 47). No plano simbólico, a barriga também reforçou a conduta egoísta, voltada apenas para o seu bem-estar, sentido propagado durante a circulação do Cabrião e, anteriormente, no Diabo Coxo.

De forma sutil, a resposta do personagem da revista diante da cena apontou a interferência dos jesuítas na comunidade e na vida privada a partir de seus comentários sobre a "vida alheia". Na definição de um suposto dicionário, o periódico informou o significado da palavra "jesuíta".

[...] Jesuíta - Frade da Companhia de Jesus, instituida pelo visionario Ignacio de Loyola. - Animal degradado, que abdica os fóros de racional para tornar-se instrumento cego e feroz dos interesses da ordem a que pertence. Encarnação da hypocrisia. - Homem cousa. - Ente desnecessario, pertencente á uma seita não só inutil, como perigosa e nociva. - Symbolo da estupidez, galvanisada pelo fanatismo. [...] - Symbolo da ambição do ouro e do mando, sob a capa do desinteresse e da mansidão. - $\mathrm{O}$ maior desacreditador da religião de Christo. - Optimo obreiro da superstição. Inimigo nato da razão e da consciencia humana. [...] - Acerrimo inimigo do povo, da democracia e da soberania popular. - Servil bajulador dos grandes da terra, e carrasco impassivel da populaça miuda. [...] - Corruptor de meninos e mulheres por meio do confessionario e do ensino. [...] - Habil aproveitador dos segredos domesticos apanhados no confessionario. [...] Sanguesuga insaciavel dos pobres de espirito e dos tolos (Cabrião, 2000 [1866], p. 63).

Os sentidos da palavra foram baseados na visão ideológica do Cabrião e condensou em linhas gerais as suas principais concepções sobre a instituição: a sua faceta "irracional", "supersticiosa", uma seita "inútil, perigosa e nociva" para o seu século, "símbolo da estupidez" e do "fanatismo", ou seja, grupo contrário a "modernização" da sociedade. Um dos perigos de sua existência estaria na habilidade de aproveitar dos "segredos domésticos apanhados no confessionário" e da "corrupção" de "meninos e meninas" através do ensino para mobilizar a opinião pública de acordo com os interesses "da ordem a que pertence" e dos "grandes da terra". Nas pequenas cidades, o controle social exigia das pessoas consideradas notáveis uma reputação impecável e o poder de difamação de um pároco local, conhecedor dos piores segredos das famílias, poderia arruinar uma carreira política ou o seu prestígio. 
Cabrião: o debate político no Segundo Reinado por meio das caricaturas de Angelo Agostini Danilo Aparecido Champan Rocha; Sandra de Cássia Araújo Pelegrini

Apesar de representantes oficiais do cristianismo católico, os jesuítas foram entendidos como o "maior desacreditador da religião de Cristo", "inimigos do povo", “carrasco da população miúda" e "sanguessugas dos pobres de espírito e dos tolos". Sobre esse último ponto, Agostini satirizou em uma caricatura essa relação entre a fé e a exploração de pessoas "imbecis" e humildes pelos frades, com a doação de seus parcos recursos sob o pretexto do sacrifício na terra ser recompensado no céu (Cabrião, 2000 [1867], p. 197). Em outro momento, tidos como a "encarnação da hipocrisia", os jesuítas disfarçavam os seus desejos de riqueza e poder através da "capa do desinteresse e da mansidão", como representado na caricatura abaixo.

Figura 2: "fazei o que eu digo, mas não façais o que eu faço".

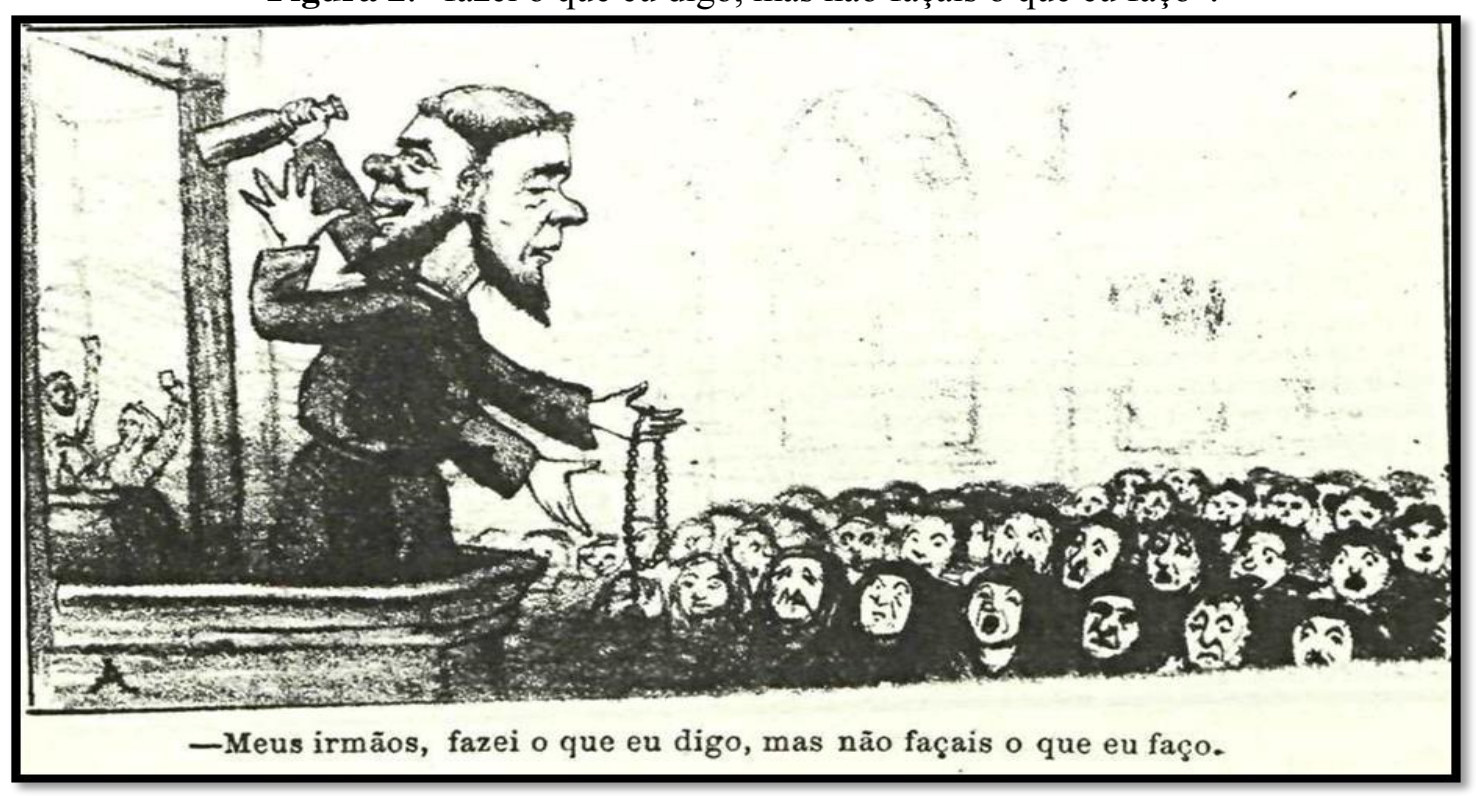

Fonte: Cabrião, São Paulo, n. 8, 1866, p. 61.

De forma a deslegitimar o apelo moralista de religiosos sobre a população, as caricaturas do semanário denunciavam a ganância e a hipocrisia dos jesuítas nas suas condutas cotidianas. Nessa imagem, Agostini habilmente transmitiu essa dualidade nas ações dos "barbudos" de samarra ao construir uma cena polifônica, dividida entre o espaço público, de aparições e condutas calculadas por estarem em constante avaliação da multidão de fiéis, e o espaço privado, área oculta, restrita e discreta.

O membro da Companhia de Jesus, caracterizado pela roupa preta e o rosário na mão, pregava do alto de uma sacada para um numeroso público, todos em uma postura obediente escutando a exposição, composto por homens e mulheres, diferenciação explícita pelo uso de 
véu e pelo corte de cabelo. No seu verso, uma imagem refletida de si levanta uma garrafa na direção de sua boca, gesto que sugere a ingestão de seu conteúdo, provavelmente alcoólico para denotar uma falha no caráter e fundamentar a denúncia do "vício". O consumo da bebida torna-se evidente ao observarmos no plano de fundo, do lado oposto da multidão, duas pessoas erguendo os copos e uma garrafa em cima da mesa. A fisionomia expansiva e alegre do jesuíta com a garrafa na mão em oposição a figura calma e solene demonstra a dissimulação desses agentes religiosos como ressaltado pela legenda "fazei o que eu digo, mas não façais o que eu faço".

Interessante destacarmos como essa crítica frequente sobre a gula, a hipocrisia e o fanatismo supersticioso dos jesuítas e, simultaneamente, dos protestantes não foram atribuídos a toda manifestação religiosa ou expressão de religiosidade. Os ataques direcionados a esse segmento eclesiástico foi derivado de sua rigidez em aceitar qualquer conhecimento ou conteúdo que fosse contrário aos preceitos bíblicos e a sua intervenção "nociva" nas instâncias de poder do Estado. Nessas condições, a ignorância, a intolerância e a superstição eram consideradas formas de "atraso" e antagônicas da razão e da ciência promovidas pelo "progresso" do "mundo civilizado" defendido pelo semanário humorístico.

Inclusive, o Cabrião se apresentou enquanto religioso, mas sem hipocrisia, em um dos anúncios no Correio Paulistano ${ }^{5}$, periódico também redigido por Américo de Campos (SANTOS, 2000). Em outro momento, em uma de suas publicações, o semanário ilustrado condenou a conduta "desdenhosa e desrespeitosa" de ateus diante da procissão de domingo e solicitou a intervenção da polícia nesses casos para "fazer respeitar a liberdade de consciência em matéria de religião" (Cabrião, 2000 [1866], p. 54). No entanto, como o próprio semanário alertou, não era do seu interesse que os leitores aderissem ao "sórdido e grosseiro beatério pregado pelos ardilosos jesuítas", mas que houvesse nestas relações um equilíbrio entre a racionalidade e a religião.

Nesse movimento ambíguo, o Cabrião rejeitou a postura e as bandeiras "retrógradas" do jesuitismo e do conservadorismo, sem se desvencilhar da fé cristã. A oposição aos integrantes do clero era decorrente de seu potencial político para mobilização do eleitorado, a sua intromissão nos assuntos públicos para impedir a adoção de medidas "progressistas" (como, por exemplo, o ensino laico) e na negação supersticiosa dos conhecimentos científicos. Portanto, a sua condição "nociva" não era pela crença em um ser divino, mas

5 Correio Paulistano, São Paulo, n. 3107, 1866, ano XIII, p. 01. Disponível em: <http://memoria.bn.br/pdf/090972/per090972_1866_03107.pdf>. Acessado em: 19 de fev. de 2017. 
Cabrião: o debate político no Segundo Reinado por meio das caricaturas de Angelo Agostini Danilo Aparecido Champan Rocha; Sandra de Cássia Araújo Pelegrini

estava justamente na interferência nos assuntos terrenos e no desprezo pelas transformações do porvir.

Além dos jesuítas, os conservadores também foram "homenageados" nas páginas do Cabrião. O maior representante conservador, João Mendes de Almeida, católico fervoroso (BUZAID, 1956), redator do Diário de São Paulo e correspondente da Revista Commercial ${ }^{6}$, ambos periódicos rivais do semanário ilustrado, foi figura recorrente nas caricaturas de Agostini. O humor satírico das publicações noticiava o líder saquarema em cenas comprometedoras, exposição ridícula de forte repercussão na provinciana capital, como ocorreu na caricatura abaixo.

Figura 3: João Mendes de Almeida.

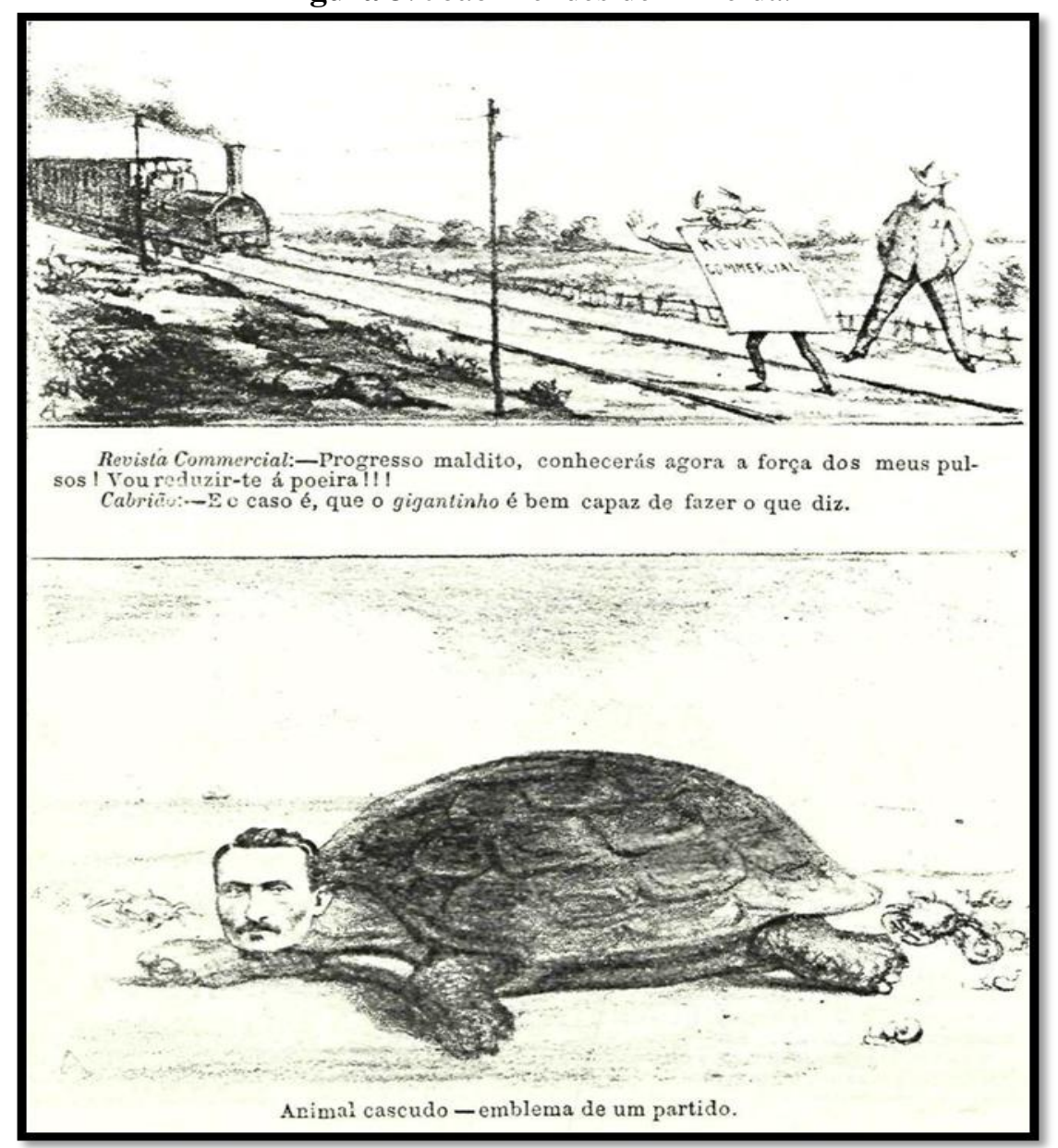

Fonte: Cabrião, São Paulo, n. 2, 1866, p. $08^{7}$

\footnotetext{
6 Correio Paulistano, São Paulo, n. 3112, 1866, ano XIII, p. 02. Disponível em: <http://memoria.bn.br/pdf/090972/per090972_1866_03112.pdf>. Acessado em: 19 de fevereiro de 2017.

${ }^{7}$ Legenda (parte superior): "Revista Commercial: - Progresso maldito, conhecerás agora as forças dos meus pulsos! Vou reduzir-te á poeira!!!”; “Cabrião: — E o caso é, que o gigantinho é bem capaz de fazer o que diz”.
}

Fronteiras: Revista de História | Dourados, MS | v. 20 |n. 35 |p. 46 - 67 | Jan. / Jun. 2018 
No primeiro quadro, pelo contexto extra-icônico, a representação da locomotiva ou da linha férrea simbolizava a modernização, a civilização e o progresso, transporte condicionado aos avanços técnicos e materiais de uma sociedade, ideais defendidas incessantemente pelo Cabrião como fundamentais para o desenvolvimento nacional. Na caricatura, a Revista Commercial, periódico santista conservador, foi posicionado no meio do trilho e a frente do trem com a intenção de parar o seu avanço por meio da força física de seus braços. $\mathrm{O}$ periódico, representado parcialmente na forma humana, com um caranguejo no lugar da cabeça e uma folha com o título do jornal no lugar do tronco, ameaçava reduzir a pó, conforme a legenda, o "progresso maldito". Ironicamente, a seleção do crustáceo na imagem era uma forma de salientar a prática dos conservadores, segundo o hebdomadário humorístico, de andar sempre para trás ou na direção ao passado, e a tentativa de interromper o "progresso" também reafirmou a conduta retrógrada dos "regressistas" diante das transformações de qualquer aspecto daquela sociedade tradicional.

O personagem Cabrião, do lado da estrada de ferro, observa a situação e, apesar da impossibilidade lógica de ser bem-sucedido no seu intento, alertou para o risco de o "gigantinho" conservador conseguir cumprir a sua promessa. O termo "gigantinho", sublinhado em itálico, ao invés de enfatizar a grandeza do periódico, zombou de um comentário da Revista Commercial sobre o surgimento e a circulação do Cabrião, na qual o definiu como um "jornalzinho" (Cabrião, 2000 [1866], p. 26). Dessa forma, a probabilidade existente de impedir o "progresso" não decorria de seu tamanho e força, mas do poder político local de seus organizadores e interlocutores de mobilizar a opinião pública e as autoridades do Estado para dificultar a aprovação de medidas consideradas "modernas", "progressistas" e “civilizadas" como, por exemplo, a própria extensão do transporte ferroviário no interior da província (Cabrião, 2000 [1866], p. 99).

No quadro seguinte, João Mendes de Almeida foi retratado como uma tartaruga, outro animal considerado representativo dos conservadores, pela sua lentidão característica durante a locomoção, analogia atribuída aos membros conservadores devido à resistência de modificar as instituições ou de se adaptar as transformações do presente. O jogo de palavras irônicas na legenda, de duplo sentido, apresentou ao público o "animal cascudo", frase referente a pessoa reproduzida e a tartaruga, ambos emblemas do partido, o primeiro chefe da agremiação e o outro símbolo conservador. 
A representação de um respeitável político como João Mendes, chefe de um dos partidos brasileiros mais influentes do século XIX, provavelmente provocou o riso naquele domingo e foi alvo de comentários do público paulista. Não sabemos ao certo a reação do líder partidário diante do ocorrido, posto ao ridículo publicamente, mas deduzimos um sentimento de animosidade após a afronta e zombaria. No Cabrião, os redatores sem identificar a pessoa ofendida, ironizou e demonstrou o ressentimento gerado em um de seus alvos a partir da força política e social da caricatura em atingir a reputação criada pela imagem de "notabilidade" dos homens públicos. Na seção "cavaqueou", o semanário comentou como o "abafadinho" prometeu vingar-se da "afronta" de ter sido "biografado" pelo periódico. O "pançudo", característica que retoma a representação da pessoa egoísta preocupada apenas com os seus interesses particulares, apesar de revoltado com a situação, era o "tipo" ideal para ser caricaturado no Cabrião, "distinção" reservada as pessoas como o "pandega". Por fim, a redação sugeriu ao homem para não se irritar com a ação do humorístico, pois, não se intimidariam com a vingança prometida (Cabrião, 2000 [1866], p. $35)$.

Contudo, se um comentário ou uma caricatura já era capaz de provocar a ira de pessoas como o "abafadinho pançudo", imagina diversas passagens e imagens dedicadas à João Mendes. O enfoque dos redatores do semanário humorístico nesse mote não foi apenas pelo fato de Mendes presidir o Partido Conservador, mas também pela sua participação na redação do Diário de São Paulo, somada a sua postura extremamente religiosa e a ação judicial movida como advogado de Candido Silva, proprietário do Diário nesse período, contra a caricatura de Agostini sobre o dia de finados. Nesse sentido, essa relação entre o jesuitismo, o Diário e a figura do chefe conservador, todos os elementos considerados como manifestação de atraso e um obstáculo para o "progresso civilizatório" foi condensada na próxima caricatura. 
Figura 4: O jesuitismo do Diário de São Paulo.

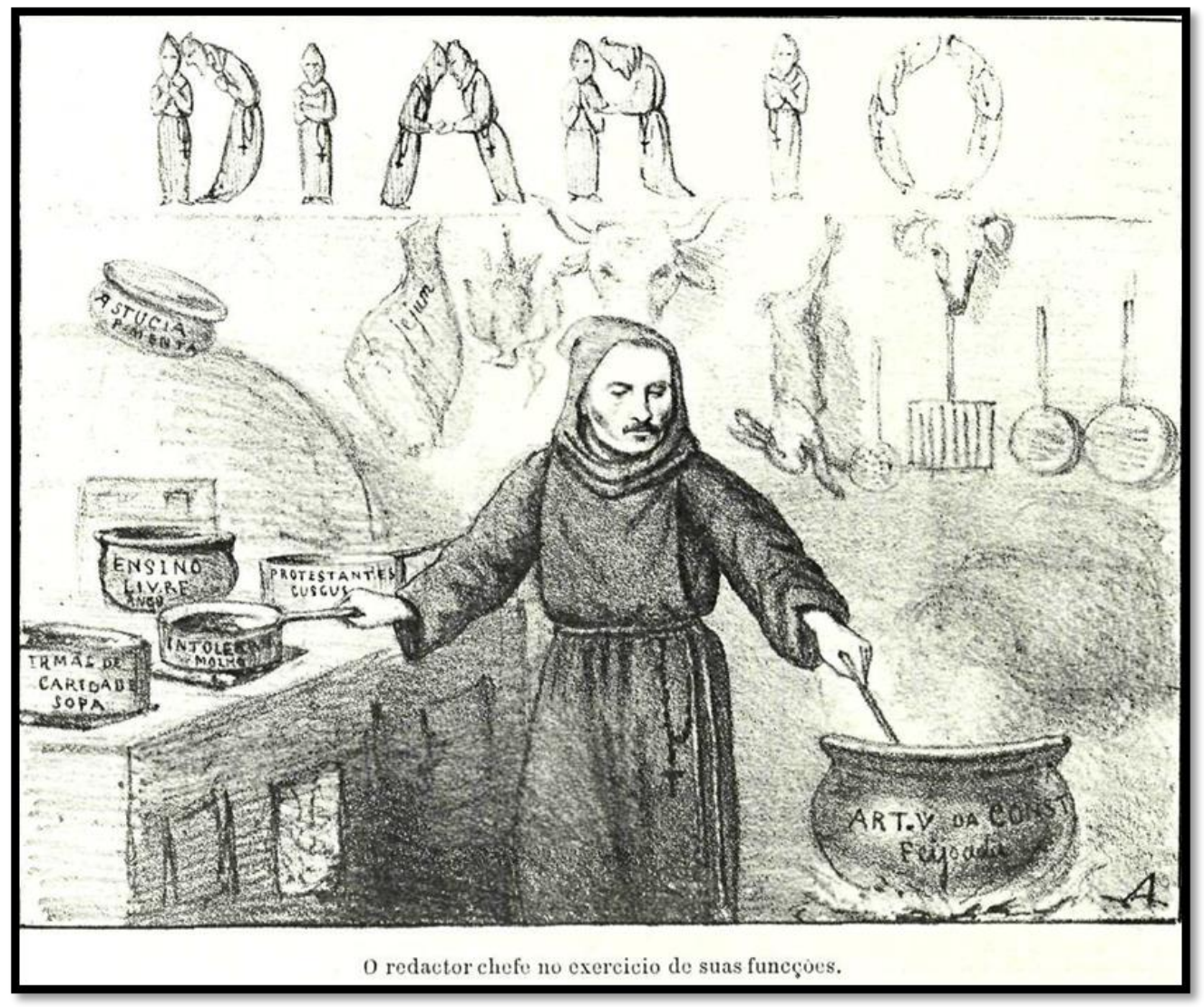

Fonte: Cabrião, São Paulo, n. 4, 1866, p. 08.

João Mendes, vestido de samarra e com um rosário na cintura, prepara uma feijoada "no exercício de suas funções", nomeada como o artigo quinto da Constituição, estatuto responsável pela união entre o Estado e a Igreja Católica, elevada a religião oficial do Império. ${ }^{8}$ Alguns ingredientes estão dispostos em cima da mesa, como a pimenta, o angu, o cuscuz, o molho e o pernil, itens referentes a astúcia, ao ensino livre, aos protestantes e ao jejum, respectivamente. A sopa, representação das irmãs de caridade, apesar de estar na mesa, configura um prato pronto, um alimento a parte da feijoada, assim como a instituição religiosa em São Paulo, ligada à Igreja Católica, mas autônoma e independente nas suas ações. O pernil, rico em gordura e proteína, contraditoriamente descrito como jejum, ação recomendada pelo clero como forma de expiação em períodos de restrição, insinua e ironiza mais uma vez a gula e a fartura nas refeições dos párocos. O angu e o cuscuz, ambos de origem africana, apesar de serem produtos típicos da culinária brasileira, não são utilizados na

\footnotetext{
${ }^{8}$ Constituição de 1824. Disponível em: 〈http://www.planalto.gov.br/ccivil_03/constituicao/constituicao24.htm〉. Acessado em: 10 de fev. 2017.
} 
preparação da feijoada. Respectivamente, o ensino livre e o protestantismo, após a reafirmação do padroado e da inclusão da instrução primária como um dos direitos civis dos cidadãos na Constituição de 1824, excluiu o culto de religiões não católicas em espaços públicos e legalizou a presença do clero nacional na educação promovida pelo estado. Por isso, tal como o angu e o cuscuz, não estavam contemplados na feijoada/Constituição.

$\mathrm{Na}$ figura 4, notamos que enquanto o líder conservador mexia a feijoada com a mão esquerda, a outra segurava uma panela de molho para adicioná-lo no caldeirão. A indicação da "intolerância" como o componente do recipiente para temperar a feijoada exibiu a percepção dos redatores sobre a elaboração do projeto de lei, marcado pela intransigência e a opressão das liberdades, fenômeno consequente do fanatismo religioso e postura reproduzida pelo "redator chefe". O pote de pimenta, posicionado um pouco mais distante do cozinheiro, do mesmo modo que a astúcia, possuí uma mordacidade "apimentada", usada em pequenas doses e sem exageros, de forma sutil e ardilosa, para atingir um gosto particular ou um resultado ambicionado.

O aspecto negativo e maligno da redação do Diário e da relação entre a Igreja e o Estado foi construído a partir da combinação da vestimenta, do ato de cozinhar no caldeirão e na decoração do ambiente com cabeças de bois e animais mortos pendurados, características estereotipadas pertencentes ao imaginário popular sobre a bruxaria e a magia negra. ${ }^{9}$ Em cima, o nome do jornal foi formado por figuras macabras encapuzadas, provavelmente, jesuítas pela semelhança entre as roupas e o uso do rosário. A derrisão sobre o Diário e seus organizadores foi uma forma de enfatizar a parcialidade de seus conteúdos, posicionamento derivado de sua postura política e religiosa, vínculo tão presente na folha que o seu título na caricatura foi até formado pelos próprios integrantes da ordem eclesiástica.

As representações e os comentários humorísticos sobre a religião e as personalidades conservadoras promoveram um sentimento de revide e desforra entre os periódicos da província paulista, como foi o caso da folha supracitada. O surgimento do Cabrião foi interpretado da seguinte forma pelos organizadores do Diário.

Sahio á luz uma folha chocarreira e boçal, com o titulo de Cabrião; - titulo que bem lhe quadra, porque Lucifer é tambem o acerrimo Cabrião do gênero humano! Tem essa folha por seu regabofe as fraquezas do próximo, e, (dobrado escândalo!) o depravado sentimento de ridicularisar o que pertence

\footnotetext{
${ }^{9}$ No número anterior, a redação do Esperança de Itu, também religioso e conservador, foi retratado com um demônio ditando os conteúdos do jornal. In: Cabrião, 2000 [1866], p. 21.
} 
á Santa Religião do Estado, assumpto que por sua sublimidade não é para os beiços dos seus redactores; mas.... cuidado que não lhes fique o osso atravessado na garganta! Não admira o apparecimento desse pasquim zurrador; o que produz um amargoso reparo é correr como certo achar-se entre esses redactores um joven que até aqui tem passado como pessoa assisada, circumspecta, geralmente estimada, e casado com uma senhora de não vulgar educação e eminentemente religiosa! (Diário de São Paulo, 1866, n. 350 , p. 02-03, grifo do autor). ${ }^{10}$

Concebido como um "pasquim", "zurrador" e "boçal", os redatores intencionaram desqualificar o semanário ilustrado como algo apenas ofensivo e injurioso e a novidade da linguagem visual como obra de "depravados" "rabiscadores" focados em "escarnecer" os defeitos alheios e "ridicularizar o que pertence a Santa Religião do Estado". Um detalhe interessante foi o pesar do Diário pela participação de um jovem estimado e "casado com uma senhora de não vulgar educação e eminentemente religiosa" na redação do Cabrião. O comentário era sobre Antonio Manoel dos Reis, homem católico, formado na Academia de Direito em 1864 e autor de livros como Minhas Inspirações, Ensaios poéticos e Album literário, obras de prestígio entre a população e os críticos literários (SANTOS, 2000). Aliás, ainda segundo Santos (2000, p. XXXIV), posteriormente a publicação do Cabrião, o jornalista, advogado e escritor aderiu ao Partido Conservador para angariar cargos e nomeações, desejo não suprido pelos seus antigos correligionários, considerados ingratos por Antonio dos Reis.

A rivalidade entre o Cabrião e o Diário durou até o fim da direção de Candido Silva, anunciado e comemorado inclusive pela revista ilustrada. O novo proprietário foi Antônio da Silva Prado ${ }^{11}$, importante liberal paulista, e as divergências entre ambas ficaram restritas aos períodos de disputas eleitorais devido a cisão do Partido Liberal.

Os ataques aos conservadores e ao clero delimitaram o outro, considerado retrógado e atrasado, mas não absteve os representantes e as lideranças liberais. Nas campanhas eleitorais e nos governos liberais da província de São Paulo, independente de pertencerem ao mesmo partido, os redatores dedicaram parte de seus conteúdos para a avaliação da administração e da postura de personalidades do Partido Liberal. As menções negativas a Tavares Bastos,

10 Diário de São Paulo, São Paulo, n. 350, 1866, ano II, p. 02-03. Disponível em: <http://memoria.bn.br/pdf/709557/per709557_1866_00350.pdf>. Acessado em: 8 de fevereiro de 2017.

11 Diário de São Paulo, São Paulo, n. 398, 1866, ano II, p. 03. Disponível em: <http://memoria.bn.br/pdf/709557/per709557_1866_00398.pdf>. Acessado em: 8 de fevereiro de 2017. 
Cabrião: o debate político no Segundo Reinado por meio das caricaturas de Angelo Agostini Danilo Aparecido Champan Rocha; Sandra de Cássia Araújo Pelegrini

presidente da província de São Paulo, e ao gabinete de Zacarias de Góis ${ }^{12}$ e Vasconcelos transformaram o periódico em uma figura indesejada tanto pelos conservadores quanto por seus correligionários. A perseguição de todas as direções foi destacada na seção "Horas de desespero".

Estou triste! Triste como o desgraçado que vio eclipsar-se o brilho da sua estrella! Não sei que mal tenho feito aos homens, para ve-los conspirados contra mim. Sempre amei a verdade, sempre guiei-me pela vereda do justo; sobre a minha fronte ainda joven não peza o remorso de um crime. [...] De tantos amigos que eu possuia, bem poucos me restam hoje! Muitos amigos atraiçoáram-me no momento em que eu enchia de beneficios; outros desappareceram como o relampago, desde que me viram em luta com a adversidade (Cabrião, 2000 [1867], p. 190).

As consequências de criticar tudo e todos comprometeram a manutenção e a continuidade da circulação da revista. O "abandono" crescente de membros liberais das fileiras do Cabrião ocorreu conforme recrudesceu o seu posicionamento sobre temas como as campanhas eleitorais, o recrutamento militar e a questão religiosa. Qualquer candidato com ambições de ascender na ocupação de cargos na capital paulista precisava aderir as determinações do partido, condição conflitante com as representações pejorativas das principais lideranças partidárias no semanário.

Uma dessas lideranças, Tavares Bastos, presidente da província de São Paulo, foi criticado e responsabilizado pelas ações arbitrárias de autoridades políticas locais ao desrespeitarem à Constituição no decorrer da política de recrutamento para a guerra do Paraguai. Nesse sentido, o despotismo do aparelho de Estado, reproduzido no alistamento forçado de pessoas legalmente dispensadas dos serviços militares, e a corrupção para a isenção das pessoas "apadrinhadas" receberam destaque nas suas publicações.

\footnotetext{
12 A corrupção contida nas vendas de condecorações, o aumento dos impostos e o prolongamento da guerra, entre outros aspectos, foram alguns dos problemas associados a administração do gabinete de Zacarias de Góis e de seus ministros. A título de exemplo, em duas caricaturas, os fenômenos citados acima foram representados por Agostini, ver: Cabrião, 2000 [1867], p. 120 e Cabrião, 2000 [1867], p. 295.
} 
Cabrião: o debate político no Segundo Reinado por meio das caricaturas de Angelo Agostini Danilo Aparecido Champan Rocha; Sandra de Cássia Araújo Pelegrini

Figura 5: A violência do recrutamento e a indignação da opinião pública.

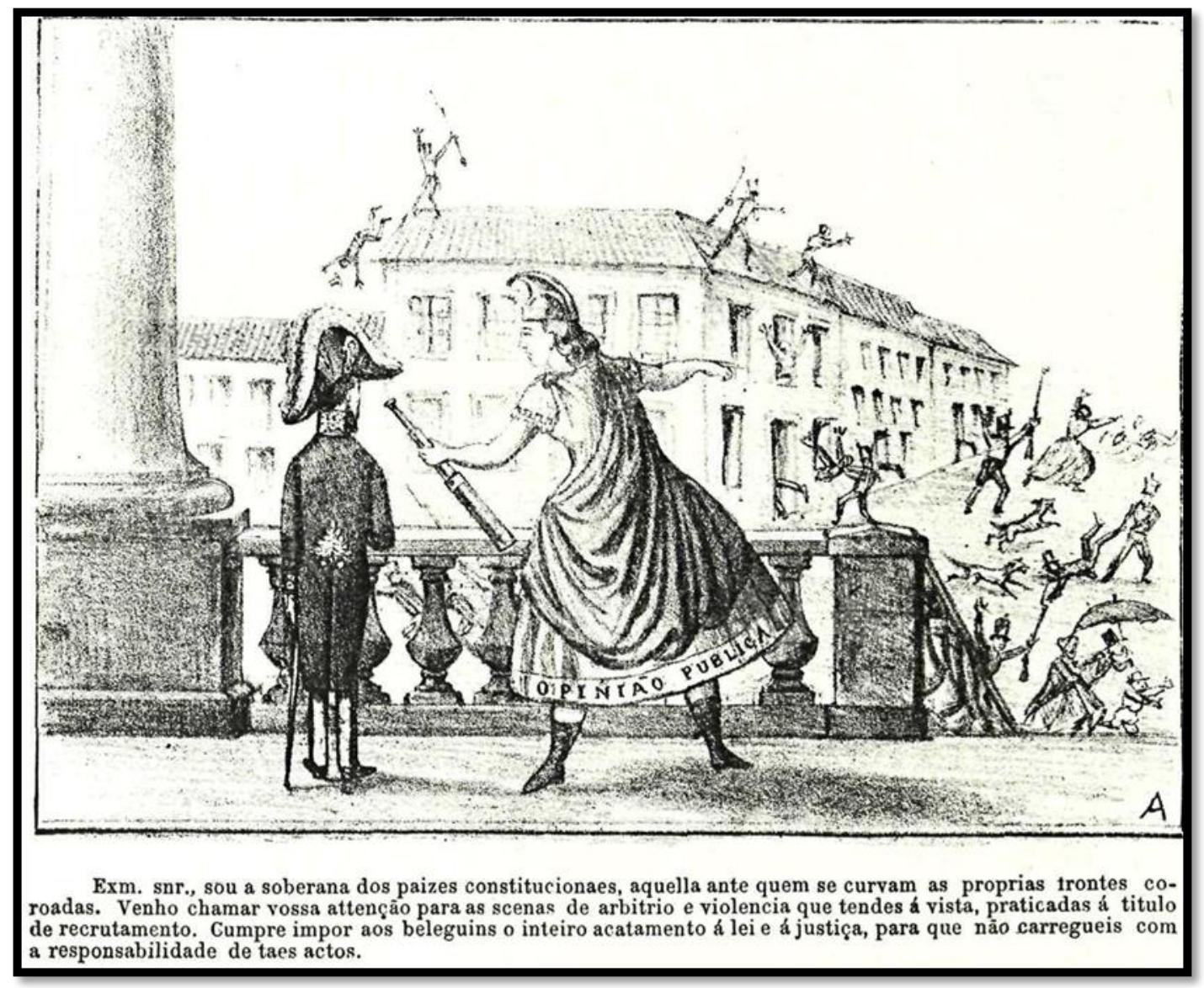

Fonte: Cabrião, São Paulo, n. 10, 1866, p. 08.

Na legenda, a representação da opinião pública chama a atenção de uma autoridade política, provavelmente José Tavares Bastos, para acabar com os casos de "arbítrio e violência praticados a título de recrutamento" na capital paulista. De longe, no segundo plano, guardas nacionais armados atacam quem está passando na rua e a confusão generalizada foi construída por meio da fuga para todos os lados de homens, mulheres, crianças e até de cachorros. A busca por assentar praças é tão incisiva que guardas perseguem potenciais recrutas pelos telhados e janelas dos prédios e um dos homens é arrastado pelos pés para o quartel. A “opinião pública”, indignada com a situação, aponta com a mão direita para a confusão e entrega uma luneta para o presidente, ato ignorado pelo mesmo.

No entanto, sem recuos e diante de tal arbítrio, os redatores cobraram um posicionamento até do monarca para coibir os abusos. 
Figura 6: "Constituição: a Soberana nacional".

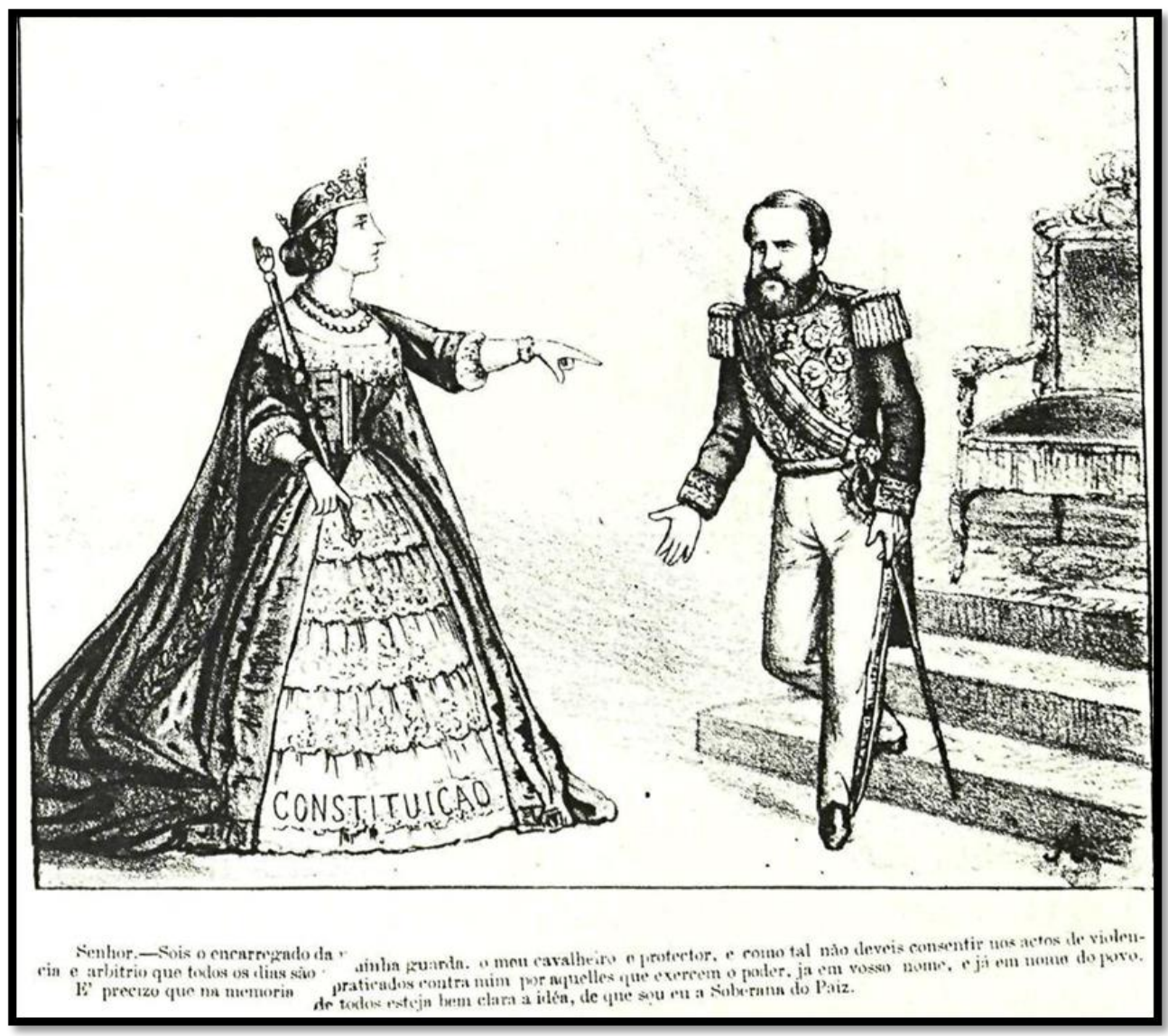

Fonte: Cabrião, São Paulo, n. 26, 1867, p. $04^{13}$

No contexto intra-icônico da caricatura, uma mulher majestosamente vestida, representada como a Constituição, com o livro de "lei" debaixo do braço e com o dedo em riste para D. Pedro II, exigiu a aplicação de suas regras e determinações, em defesa do povo, frequentemente desrespeitado pelos "atos de violência e arbítrio" praticados pelas autoridades no poder. Dessa forma, a cena construiu uma posição ativa e de autoridade da mulher/constituição, percepção reforçada pela resposta gestual do monarca com a mão direita aberta como se tentasse explicar e se eximir da culpa imputada. A imagem expressou uma das concepções de uma ala liberal sobre a supremacia do poder constitucional e a necessidade de supressão do poder Moderador do monarca, como destacou a fala da Constituição na legenda ao afirmar-se a "Soberana do país". Para ouvir as inquietações e as exigências, o imperador desceu de seu trono, posicionado acima do nível do chão, comportamento que enfatizou, sem

\footnotetext{
${ }^{13}$ Legenda: "Senhor. - Sois o encarregado da minha guarda, o meu cavalheiro e protector, e como tal não deveis consentir nos actos de violencia e arbitrio que todos os dias são praticados contra mim por aquelles que exercem o poder, já em vosso nome, e já em nome do povo. É precizo que na memoria de todos esteja bem clara a idéia, de que sou eu a Soberana do Paiz".
} 
Cabrião: o debate político no Segundo Reinado por meio das caricaturas de Angelo Agostini Danilo Aparecido Champan Rocha; Sandra de Cássia Araújo Pelegrini

ofender ou menosprezar a sua figura, o papel de "protetor" do Estado de direito, posição política também submetida a Constituição.

No entanto, apesar de defender a revogação do quarto poder, o Cabrião não questionou o regime monárquico e, muito menos, aderiu ao movimento republicano no período de sua circulação. O semanário era liberal, apegado aos direitos constitucionais expressos na Carta de 1823, aprovada na Assembleia antes de sua dissolução realizada por D. Pedro I. Entre as ramificações ideológicas manifestas no Partido Liberal, os redatores se associaram a facção mais radical, anticlerical, contrária as alianças com os setores considerados retrógrados.

Os desentendimentos entre os liberais se intensificavam a cada eleição e, como uma última tentativa de unificar as pautas partidárias, Agostini produziu uma caricatura para realinhar os dissidentes para que juntos combatessem o "despotismo inconstitucional”.

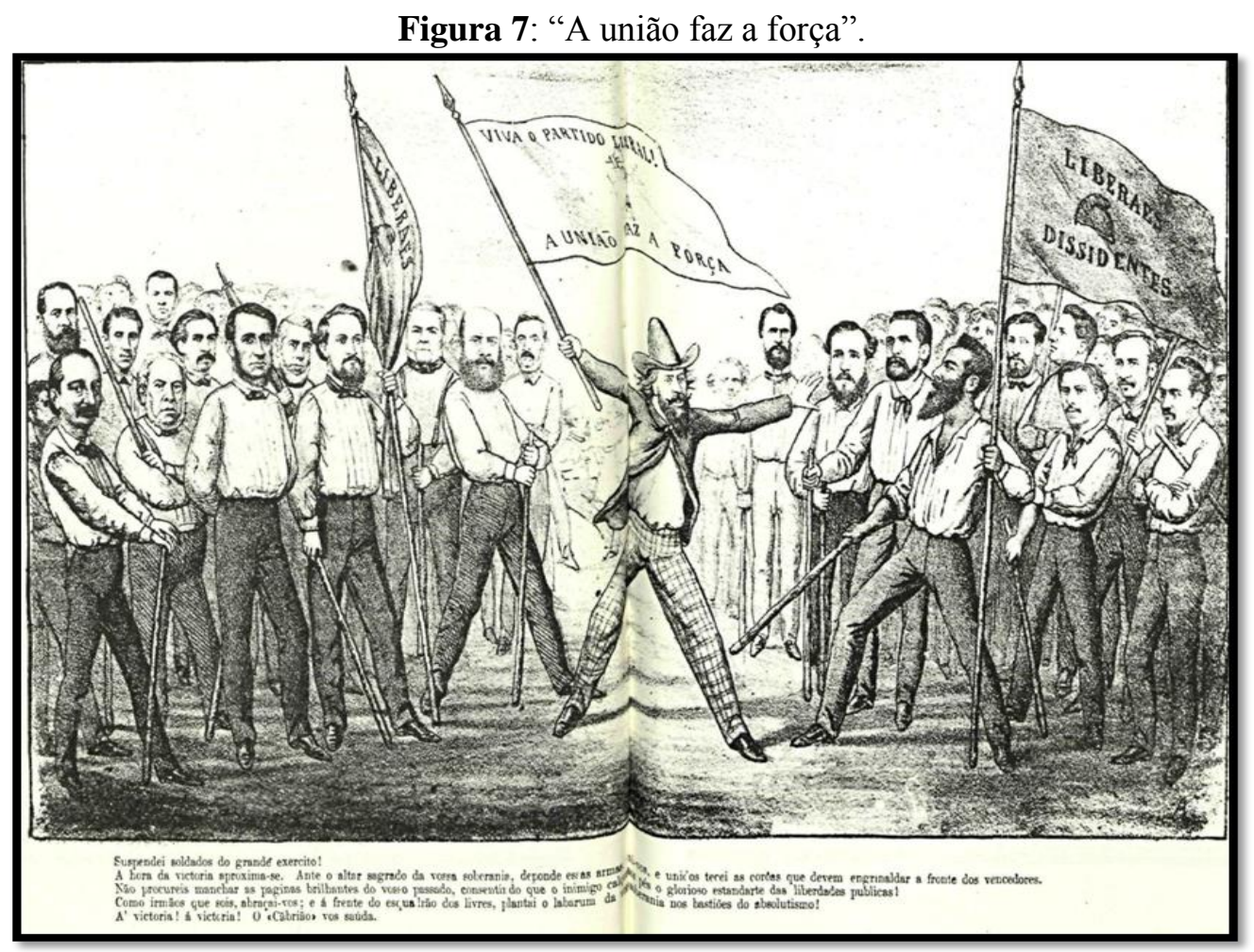

Fonte: Cabrião, São Paulo, n. 18, 1867, p. 04-05 14

\footnotetext{
${ }^{14}$ Legenda: "Suspendei soldados do grande exercito! Ahora da victoria aproxima-se. Ante o altar sagrado da vossa soberanía, deponde essas armas [palavra ilegível] e unidos tecei as corôas que devem engrinaldar a fronte dos vencedores. Não procureis manchar as paginas brilhantes do vosso passado, consentindo que o inimigo [palavra ilegível] aos pés o glorioso estandarte das liberdades publicas! Como irmãos que sois, abraçai-vos; e á frente do esquadrão dos livres, plantai o labarum da [palavra ilegível] soberania nos bastiões do absolutismo! Á victoria! Á victoria! O “Cabrião” vos saúda”.
} 
$\mathrm{Na}$ imagem, o piemontês representou as principais lideranças de cada facção, divididos em liberais e liberais dissidentes. Do lado esquerdo, Bonifácio lidera os "liberais" com a bandeira na mão, acompanhado à sua esquerda do brigadeiro Bernardo José Pinto Gavião Peixoto, presidente da província paulista entre 1847 e 1848, de João da Silva Carrão na sua direita, também presidente de São Paulo entre 1865 e 1866, seguido um pouco mais ao fundo por Joaquim Floriano de Toledo, vice-presidente de Carrão, figura inclusive homenageada pelo Cabrião no fim de seu mandato em $1866 .{ }^{15}$ Segundo Santos (2000, p. XVIII), também estavam presentes Joaquim Roberto de Azevedo Marques, proprietário do Correio Paulistano e responsável pela impressão do primeiro trimestre do Cabrião, além de Antônio Prado, dono do Diário de São Paulo após sua fase conservadora.

Do lado direito, Luiz Gama, ex-redator do Diabo Coxo, porta a bandeira dos "liberais dissidentes", junto com Martim Francisco e Américo de Campos, ambos a sua direita. O posicionamento do redator do Cabrião na ala dissidente corrobora com a argumentação desenvolvida nesta pesquisa e, a partir do fim da conciliação em 1868, esse grupo passou a defender propostas de reforma social e política consideradas radicais, momento de ruptura partidária com o regime monárquico e escravagista.

Cada indivíduo da imagem está com um bastão na mão, o que reforça a ideia de que as "disputas" eleitorais ocorriam tanto nas urnas quanto no corpo a corpo. No centro, o personagem Cabrião clama aos seus correligionários para se unirem em um mesmo ideário liberal com o intuito de fortalecer o partido, fragilizado por suas divisões ideológicas, fragmentação demonstrada pela distribuição de seus integrantes em dois planos verticais. A frase "união faz a força" da bandeira estendida pelo Cabrião ironizou a débil situação dos liberais e alertou para a necessidade de uma base coesa caso desejassem fortalecer o partido em torno de propostas para garantir as liberdades e combater os abusos contra os direitos do cidadão. Contudo, o apelo foi ignorado por seus partidários e na eleição seguinte os conservadores venceram, acontecimento comentado e retratado inúmeras vezes no periódico. Em uma caricatura, João Mendes foi representado do alto de um mastro, posicionado de modo ofensivo, celebrando a vitória eleitoral juntamente com tatus e tartarugas (Cabrião, 2000 [1867], p. 129), animais que representavam as ações subterrâneas e a lentidão dos “cascudos”.

\footnotetext{
15 As informações sobre os presidentes e vice-presidentes da província de São Paulo no século pode ser consultada em: EGAS, Eugenio. Galeria dos presidentes de São Paulo: periodo monarchico 1822-1889. São Paulo: Publicação Official do Estado de São Paulo, 1926.
} 
O desânimo e a indignação dos redatores com os resultados eleitorais acentuaram a oposição ao governo de Tavares Bastos, além de criticar de forma mais incisiva as personalidades liberais envolvidas em alianças políticas e, até mesmo, os periódicos liberais da base governista como o Diário (Antônio Prado) e o Correio Paulistano (Azevedo Marques). $\mathrm{O}$ isolamento progressivo do semanário apenas aumentava ao atacar os conservadores, os jesuítas, as irmãs de caridade, os protestantes, o clero nacional, os deputados regionais, os juízes, as forças policiais, entre tantos outros segmentos urbanos e rurais presentes no cotidiano da província paulista. Se o aspecto político atraiu diversos problemas para o semanário, a questão religiosa ajudou a torná-lo intolerável. No número $51^{\circ}$, no dia 29 de setembro de 1867, com suas finanças arruinadas, o até breve dos redatores se transformou em um adeus para seus assinantes.

\section{CONSIDERAÇÕES FINAIS}

A fundação do Cabrião, em 1866, representou a consolidação da revista ilustrada como meio de difusão de notícias e valores culturais na imprensa paulistana, cujo único exemplar anterior foi o Diabo Coxo, periódico também ilustrado por Angelo Agostini. As ideias defendidas pelos redatores do Cabrião estavam calcadas nas concepções ideológicas do partido liberal, porém, mais alinhadas as posturas políticas da facção considerada "exaltada", favorável ao ensino laico, a separação da Igreja do Estado, de uma descentralização política e de um conceito de progresso associado a cultura eurocêntrica. As considerações negativas do Cabrião sobre os seus opositores e desafetos como os conservadores, os jesuítas, determinadas personalidades liberais, as forças policiais a nível local, entre outros segmentos, deterioraram a durabilidade da circulação do periódico. As ações de seus adversários extrapolaram ocasionalmente o embate jornalístico e, no decorrer das publicações, a redação foi depredada, seus funcionários e leitores vítimas de perseguições políticas, os redatores ameaçados fisicamente e processados judicialmente. Dessa forma, isolado politicamente e arruinado financeiramente, o Cabrião não resistiu e terminou a sua impressão no término de seu primeiro ano. 


\section{FONTES DOCUMENTAIS}

AGOSTINI, Ângelo; CAMPOS, Américo de; REIS, Antônio Manoel dos. Cabrião: 18661867. 2. Ed. São Paulo: Editora UNESP; Imprensa Oficial do Estado, 2000.

BRASIL. Constituição (1824). Constituição política do Império do Brasil.

Correio Paulistano, São Paulo, n. 3107, 1866, ano XIII.

Correio Paulistano, São Paulo, n. 3112, 1866, ano XIII.

Diário de São Paulo, São Paulo, n. 350, 1866, ano II.

Diário de São Paulo, São Paulo, n. 398, 1866, ano II.

\section{REFERÊNCIAS BIBLIOGRÁFICAS}

BUZAID, Alfredo. João Mendes de Almeida Jr. - aspectos de uma grande vida. In: Revista da Faculdade de Direito da Universidade de São Paulo, São Paulo, v. 51, p. 73-97, 1956.

CARDOSO, Rafael. Projeto gráfico e meio editorial nas revistas ilustradas do Segundo Reinado. In: KNAUSS, Paulo; MALTA Marize; OLIVEIRA, Cláudia de; VELLOSO, Mônica Pimenta (Orgs.). Revistas Ilustradas: modos de ver e ler no Segundo Reinado. Rio de Janeiro: Mauad X: FAPERJ, 2011, p. 18-66.

EGAS, Eugenio. Galeria dos presidentes de São Paulo: periodo monarchico 1822-1889. São Paulo: Publicação Official do Estado de São Paulo, 1926.

FONSECA, Joaquim da. Caricatura: a imagem gráfica do humor. Porto Alegre: Artes e Ofício, 1999.

MINOIS, Georges. História do riso e do escárnio. São Paulo: Editora UNESP, 2003.

NERY, Laura. Os sentidos do humor: Henrique Fleiuss e as possibilidades de uma sátira bemcomportada. In: KNAUSS, Paulo; MALTA Marize; OLIVEIRA, Cláudia de; VELLOSO, Mônica Pimenta (Orgs.). Revistas Ilustradas: modos de ver e ler no Segundo Reinado. Rio de Janeiro: Mauad X: FAPERJ, 2011, p. 173-187.

SANTOS, Délio Freire dos. Primórdios da imprensa caricata paulistana: o Cabrião. In: AGOSTINI, Ângelo; CAMPOS, Américo de; REIS, Antônio Manoel dos. Cabrião: 18661867. 2. Ed. São Paulo: Editora UNESP; Imprensa Oficial do Estado, 2000, p. XI-XLV.

SODRÉ, Nelson. História da imprensa no Brasil. 4. Ed. Rio de Janeiro: Mauad, 1999. 